УДК 130.2

$10.17213 / 2075-2067-2021-1-284-290$

\title{
ПРОБЛЕМА СМЫСЛА ЖИЗНИ ЧЕЛОВЕКА В РАБОТАХ РУССКИХ РЕЛИГИОЗНЫХ ФИЛОСОФОВ
}

\author{
(C) 2021 г. П. А. Пономарев*, А. В. Панычик**
}

\section{"Донской государственный технический университет, г. Ростов-на-Дону, Россия "Ростовский государственный экономический университет (РИНХ), 2. Ростов-на-Дону, Россия}

Целью исследования является анализ творчества русских религиозных философов конца XIX - начала XX века, посвященного проблеме смысла жизни.

Теоретико-методологические основы исследования обусловлены приверженностью авторов к религиозно-идеалистическому пониманию бытия человека. B статье использован системный подход, позволивщий рассмотреть конщепџии смысла жизни в русской религиозной философии как взаимосвязи элементов в системе отношений «человек мир - Бог». Использование аналитического метода способствовало определению подходов религиозных философов к трактовке проблемы с учетом эволюччи их мировоззрений. Диалектический метод обеспечил всестороннее рассмотрение причинно-следственных связей явлений и процессов в динамике их развития. Принцип историзма обеспечил реконструкцию развития концепции смысла жизни в работах русских религиозных философов, что позволило рассмотреть в единстве историческое и логическое.

Результаты исследования. В условиях кризиса общественной морали, навязываемой средствами массовой коммуникации идеологии быстрого обогащчения и потребления, христианский смысл жизни, концептуально обоснованный русскими религиозными философами, должен стать духовной базой консолидащии и солидарности людей на основе признаваемых ими конечных смыслов универсума.

Перспективу исследования составляет дальнейший анализ творчества русских религиозных философов.

Ключевые слова: Бог; вера; смысл жизни; философия; человек; религия; соборность.

\section{THE PROBLEM OF THE MEANING OF HUMAN LIFE IN THE WORKS OF RUSSIAN RELIGIOUS PHILOSOPHERS}

\author{
(C) 2021 P. A. Ponomarev*, A. V. Panychik** \\ "Don State Technical University, Rostov-on-Don, Russia \\ ${ }^{* *}$ Rostov State University of Economics (RSUE), Rostov-on-Don, Russia
}

The aim of the research is to analyze the creativity of Russian religious philosophers of the late $X I X$ - early XX centuries. The twentieth century, dedicated to the problem of the meaning of life.

The theoretical and methodological foundations of the study are determined by the authors 'commitment to a religious and idealistic understanding of human existence. The article uses a systematic approach that allows us to consider the concepts of the meaning of life in Russian religious philosophy as the relationship of elements in the system of relations between 
«human - world - God». The use of the analytical method helped to determine the approaches of religious philosophers to the interpretation of the problem, taking into account the evolution of their worldviews. The dialectical method provided a comprehensive consideration of the causeand-effect relationships of phenomena and processes in the dynamics of their development. The principle of historicism provided a reconstruction of the development of the concept of the meaning of life in the works of Russian religious philosophers, which allowed us to consider the historical and logical in unity.

Results of the study. In the crisis of public morality imposed by mass communication ideology of rapid enrichment and consumption Christian meaning of life, conceptually grounded by Russian religious philosophers, should become the spiritual base consolidation and solidarity of people on the basis that they recognize and the ultimate meaning of the universe.

The future of the research is the further analysis of the creativity of Russian religious philosophers.

Key words: God; faith; meaning of life; philosophy; man; religion; conciliarity.

Введение. Смысл жизни является вечной проблемой. Стремление к его постижению свойственно каждому человеку, который рано или поздно вынужден искать свое место в мире, свою причастность ко всему, что происходит в природе и Вселенной. Наиболее часто смысл жизни определяется тем значением, которое предметам, событиям и явлениям придает человек, определяя себе их важность для собственного существования.

Проблема смысла жизни приобретает в настоящее время особую актуальность в связи с обострением жизненных проблем многих людей в условиях потери прежних нравственных ценностей и ориентиров, жизненных смыслов как общественного, так и личного бытия. Целью статьи является анализ творчества русских религиозных философов конца XIX - начала XX века, посвященного проблеме смысла жизни. Исходя из признания общей значимости проблемы смысла жизни и того вклада, который внесли русские религиозные философы конца XIX - начала XX века в его изучение, можно сказать, что приобретает особую значимость их философское наследие, которое помогает в осмыслении и решении современных проблем. Актуальность русской религиозной философии обусловлена гуманистической направленностью, утверждением первичной важности для личности смысла жизни, его центрального места в воспитательном процессе.

Проблема смысла жизни занимает важное место в мировой философии. В философ- ской традиции, начиная с Демокрита и Сократа, смысл жизни был тесно связан с представлением достойной жизни, отвечающей высшим (духовным) ценностям. Смысл жизни ассоциировался с понятием блага. Вместе с тем следует отметить, что в рассматриваемый период (конец XIX - начало XX века) в европейской философской мысли наблюдалось отсутствие метафизических оснований в постановке вопроса о смысле жизни. Модная в то время философия пессимизма А. Шопенгауэра и Э. фон Гартмана утверждала онтологическую пустоту человеческого существования, лишенного смысла. В важнейших направлениях немецкой философской мысли - неокантианстве и философии жизни - также господствовало понимание разорванности единого мирового целого на сферу бессмысленной жизни и безжизненных ценностей. Разум согласно этим учениям мог звать к одной лишь цели - уничтожению жизни, точнее, самоотрицанию воли, являющейся субстанциональной основой жизни.

В то же время проблема смысла жизни получила оригинальную разностороннюю и глубокую разработку в русской религиозной философии, которая выступала в качестве оппонента зарубежным философским учениям. Своеобразие русской религиозной этической мысли заключалось в том, что формируясь под большим влиянием мировой философии, она развивалась на мировоззренческой базе этической концепции православия. Полагая, что основания морали находят- 
ся в божественном абсолюте, русские религиозные мыслители сочетали идею морально суверенной личности с изначальной коллективностью человеческого существования, которая предполагала религиозно-духовную всечеловеческую соборность. В работах русских религиозных философов конца XIX начала XX века (В. С. Соловьев, Е.Н. Трубецкой, А.Н. Бердяев и др.) вера в Бога являлась главным условием наличия смысла жизни. При этом поиски смысла жизни предполагали необходимость спасения души как условие спасения мира.

\section{Философские концепции смысла жиз-} ни. Центральной фигурой религиозной философии второй половины XIX века был В.С. Соловьев, внесший большой вклад в разработку проблемы смысла жизни. Он считал, что преодоление несовершенств жизни и победа истины, добра и красоты над пороками возможна в «богочеловеческом процессе», в котором главное - вера в Бога, служение абсолютному добру и стремление укоренить «Царство Божие». Он считал ошибочной эстетическую трактовку смысла жизни Ф. Ницше, который полагал, что смысл заключается в жизни, воплощающей силу и величественную красоту. В.С. Соловьев утверждал, что сила и красота должны быть сопряжены с добром и нравственный смысл жизни человека - служение Добру. В своей работе «Нравственный смысл жизни в его предварительном понятии» мыслитель пишет: «Нравственный смысл жизни первоначально и окончательно определяется самим добром, доступным нам внутренне через нашу совесть и разум» [4, с. 112]. Задача человека как духовного существа, по его мнению, заключается в борьбе со всеми проявлениями зла и несовершенства. Это вытекает из триады в этике В.С. Соловьева: несовершенство - в нас, совершенство - в Боге, совершенствование - как жизненная задача человека. Стремление к совершенному добру должно основываться на любви к Богу и людям, причем для достижения общества, построенного на принципах справедливости, люди должны действовать не изолированно, а совместно.

Развивая религиозно-философские взгляды В.С. Соловьева, Е.Н. Трубецкой смысл жизни рассматривал не только в качестве ценности, идеала, но и в качестве высшей истины. В книге «Смысл жизни» он писал, что смысл-истина еще не совпадает со смысломцелью, ценностью. Постичь смысл того или иного явления означает вывести его к безусловной истине, безусловной цели жизни. Открыть смысл жизни - значит оправдать жизнь. Е.Н. Трубецкой утверждал, что каждый человек сознательно или бессознательно определяет такую цель или ценность, ради которой стоит жить. Эта цель (или смысл жизни) - есть предположение неустранимое, необходимо связанное с жизнью, вот почему люди находятся в постоянном поиске смысла жизни. «Всякое движение нашей мысли, всякий акт нашей воли, - писал Е.Н. Трубецкой, - более того, весь наш жизненный процесс построен на том предположении, что есть неиссякающий источник нетленной, неумирающей жизни, что человек может действительно с ним соединиться и увековечить себя в нем. Жизнь в самом деле предполагает тот добрый смысл, который был найден в ней Платоном, иначе она не может быть оправдана» $[5$, с. 88$]$.

Философ отмечал, что в процессе поиска смысла жизни требуется духовный подъем и решительная борьба с земными страстями. Никакие лишения, страдания, временные успехи не должны останавливать человека на пути поиска смысла жизни. Согласно работам Е.Н. Трубецкого, смысл жизни есть общезначимая мысль о всеобщей и безусловной ценности, обязательной для всех. Существует только мировой смысл, заключающийся в вере в Христа, в его воскрешение.

Большое внимание проблеме смысла жизни уделял в своем творчестве Н.А. Бердяев. По его мнению, жизнь должна иметь смысл, чтобы быть благом и ценностью. Но смысл не может быть почерпнут из самой жизни. Он должен возвышаться над жизнью. Н.А. Бердяев считал, что смысл жизни человека всегда исходит от Бога. Человек обладает огромным творческим потенциалом и в то же время вынужден подчиняться материальной необходимости. Тело и дух человека находится в плену у «мира», призрачного бытия, и его задачей является освобождение духа из плена и выход из рабства в свободу, из вражды «мира» в «космическую любовь». 
А это возможно лишь благодаря творческой деятельности человека, которую Н.А. Бердяев понимал как обязанность человека перед Богом и перед самим собой. Философ считал, что творчество как переход из небытия в бытие «по существу есть выход из себя». Творчество является реализацией воли Бога. Творчество не детерминировано, а свободно, не завершено, всегда открыто и обращено к будущему. Созданный Богом мир также не завершен и продолжает твориться, но уже человеком, который должен быть свободен. В этом процессе заключается, по мнению Н.А. Бердяева, переход к Богочеловечеству. В своей подлинной свободе человек божественен. Философ писал: «Человек был создан для того, чтобы стать в свою очередь Творцом. Он призван к творческой работе в мире, он продолжает творение мира» [2, с. 69]. Н.А. Бердяев утверждает, что творчество всегда имеет «индивидуально-личностный» характер и смысл жизни человека всегда исходит от Бога.

Деятельность по реализации смысла жизни происходит во временных рамках, при этом осуществляется связь между прошлым, настоящим и будущим, связь, благодаря которой существование человека принимает форму исторического бытия. Специфика исторического бытия в том, что оно налагает ответственность, имеющее конкретный характер для каждого конкретного человека. Ответственность сопряжена с определенной системой ценностей, которая повелительно определяет деятельность человека. Смысл жизни и состоит в том, чтобы эту систему ценностей индивидуально творчески претворить в конкретной жизни [6].

Проблема нахождения смысла жизни, по мнению философа, связана с правильным пониманием сущности и назначения человека. Человек имеет двойную сферу проявления своего существования: внешнюю (окружающий мир) и внутреннюю (духовный мир). Смысл жизни нельзя обрести во внешней среде, потому что она оторвана от высшего смысла. Именно в духовном мире обретается смысл. Он предполагает связь. Эта связь не с чем-то внешним, которое бессмысленно, поскольку оно преходяще и конечно, а с неким высшим, которое дает жизнь, бессмертие, вечность. Пронизанный этим высшим, смысл жизни должен осуществлять связь личной человеческой судьбы с судьбами человеческой истории и мира в целом [1]. Таким образом, смысл жизни является высшей истинной ценностью, которая должна быть постигнута, принята человеком и реализована в его деятельности.

Проблема смысла жизни занимала важное место в творчестве С. Л. Франка. В своих работах он отмечал, что проблема добра и правды тесно связана с проблемой смысла жизни. Добро и правда являются теми духовными силами, которые образуют истинное существо нашего «Я». Философ утверждал, что для человека с ранней юности важна проблема «духовной значительности» и «осмысленности» жизни и понимание своего назначения. Проблема смысла жизни в его творчестве наиболее полно изложена в книге «Смысл жизни». По мнению мыслителя, для обретения смысла жизни необходимо индивидуально определить абсолютную цель (ценность), которая должна стимулировать совершенствование и осмысление жизни человека. Лишь при этом условии каждая человеческая жизнь наполняется смыслом. Следовательно, определяющим для человека оказывается его индивидуальное самоопределение в мире, взятие на себя личной ответственности за происходящее с ним и вокруг него. Осмысленная жизнь должна быть служением высшему и абсолютному благу.

Личность как индивидуальная неповторимость соразмерна и сопряжена Богу, неразрывно связана с ним. В то же время Бог сроден человеку, способствуя укоренению его в мире, являясь трансцендентным «гарантом» его бытия. Бог в людях и всегда с ними (хотя бы потенциально). Таким образом, С.Л. Франк вводит идею Богочеловечества, согласно которой за различными родами бытия обнаруживается всеединство как божественная первооснова. Свою ограниченность (конечность) и свое «внешнее» бытие человек может преодолеть только в трансцендировании, направленном как «вовне», так и «внутрь». «Вовне» ограничения снимаются через преобразование отношения «Я - Ты» в контекст «Мы». Трансцендирование «вовнутрь» характеризуется взаимопроникновением «души» и «духа», собственно и образующем личность как 
устремленность к «всеединству». Только таким образом безличное и непостижимое «Божество» обретает в конкретном единстве с каждым отдельным человеком имя «Бог», становясь близким, но по-прежнему непостижимым. Удержать это единство можно только в актах веры [3].

С.Л. Франк утверждал: чтобы жизнь имела смысл, необходимы два условия «существование Бога и наша собственная причастность ему, достижимость для нас жизни в Боге; во-вторых, чтобы мы сами, несмотря на все наше бессилие, на слепоту и губительность наших страстей, на случайность и краткосрочность нашей жизни, были не только “творениями” Бога, не только глиняной посудой, которую лепит по своему произволу горшечник, и даже не только "рабами" Бога, исполняющими Его волю подневольно и только для него, но и свободными участниками и причастниками самой божественной жизни» [7, с. 114].

Таким образом, соучастие в Божественной жизни является условием осмысления жизни человека. Постижение смысла жизни происходит в процессе молитвы и аскетической борьбы с самим собой. Именно это и есть, утверждал С.Л. Франк, основной труд человеческой жизни, единственное подлинное производительное человеческое дело «с помощью которого мы действенно осуществляем смысл жизни и в силу которого в мире действительно совершается нечто существенное, именно возрождение самой внутренней его ткани, рассеивание сил зла и наполнение мира силами добра» [7, с. 97].

Мыслитель полагал, что дело, которое должно спасти мир - это внутренняя, воспитательная работа над самим собой, а духовное совершенствование должно осуществляться в соответствии с высшими духовными ценностями. По мысли Франка, возможность достижения человеком совершенства определяется внутренним процессом самоочищения и самоопределения. Именно религиозное сознание понимается как высшая форма нравственного сознания. С.Л. Франк видел смысл жизни в ее утвержденности в вечном. По его мнению, только Бог наполняет жизнь каждого человека смыслом. Он одновременно и абсолютен, и сопричастен каждой конкретной земной человеческой жизни. Движение к Богу происходит через повседневные дела и поступки человека, которые должны быть озарены высшими духовными ценностями, определяющими осмысленность конкретной человеческой жизни. Таким образом, любовь к Богу, слияние с ним, реализация высших духовных ценностей является истинным смыслом жизни.

Заключение. Характерной особенностью русской религиозной философии второй половины XIX - начала XX века является антропоцентризм, то есть ориентированность на человека, на его судьбу, на смысл его жизни. Самобытность русских религиозных философов заключалась в стремлении глубоко понять внутренний мир человека, дать нравственную оценку его деяниям. Идейной основой философии русских религиозных мыслителей было христианское мировоззрение, которое, по их мнению, способствовало освобождению и созиданию человека, национальному сплочению. Это определяло гуманистическую направленность работ религиозных философов, их особое внимание к раскрытию диалектики божественного и человеческого.

В основе философии русских религиозных мыслителей лежат идеи всеединства, гармонии и любви. В центре философских размышлений были проблемы цели и смысла человеческого существования, которые рассматривались в тесной связи с идеей необходимости развития духовности человека [8.] Русские религиозные философы считали, что в своей подлинной сущности каждый человек мистически связан с Богом, находится в нерасторжимом единстве с божественным бытием. Для русской религиозной философии характерно не только неприятие индивидуализма в решении вопроса о смысле жизни, но и обоснование невозможности существования человечества без религии, без веры в Бога. Русская религиозная философия актуальна и в современный период. Являясь органической частью духовной жизни нации, она помогает людям найти ответы на многие «вечные» вопросы бытия.

\section{Литература}

1. Бердяев А.Н. О назначении человека. — М.: Республика, 1993. 
2. Бердяев А.Н. Философия творчества, культуры и искусства. Соч.: в 2 т. - Т. 1. М.: Мысль, 1994.

3. Всемирная энциклопедия: Философия/ Главн. науч. ред. и сост. А.А. Грицанов. - М.: АСТ, Мн.: Харвест, Современный литератор, 2001.

4. Соловьев В.C. Оправдание добра. Нравственная философия. Соч.: в 2 т. Т.2. - М.: Мысль, 1988.

5. Трубецкой Е.Н. Смысл жизни. - М.: Институт русской цивилизации, 2011.

6. Философия: учебник для вузов / Под ред. проф. Л. А. Никитич. - М.: Юнити-Дана, 2000. 2004.

7. Франк С. Л. Смысл жизни. - М.: АСТ,

8. Ponomarev P.A., Roudenko A.M., Samygin S.I. The Value of Russian religious philosophy of XIX - beginning of XX century in spiritual and moral education of young people// Mediterranean Journal of Social Sciences. 2015. - Vol. 6. — №2. - P. 1.

\section{References}

1. Berdjaev A.N. O naznachenii cheloveka [On the appointment of a person]. - Moscow: Respublika, 1993.
2. Berdjaev A.N. Filosofija tvorchestva, kul'tury i iskusstva [Philosophy of creativity, culture and art]. Soch.: v 2 t. - Vol. 1. - Moscow: Mysl', 1994.

3. Vsemirnaja jenciklopedija: Filosofija [World Encyclopedia: Philosophy] / In A.A. Gricanov (eds.). - Moscow: AST, Minsk: Harvest, Sovremennyj literator, 2001.

4. Solov'ev V.S. Opravdanie dobra. Nravstvennaja filosofija [Justification of good. Moral philosophy]. Soch.: v 2 t. - Vol. 2. - Moscow: Mysl', 1988.

5. Trubeckoj E. N. Smysl zhizni [The meaning of life]. - Moscow: Institut russkoj civilizacii, 2011.

6. Filosofija: uchebnik dlja vuzov [Philosophy: textbook for universities] / In prof. L.A. Nikitich (eds.). - Moscow: Juniti-Dana, 2000.

7. Frank S. L. Smysl zhizni [The meaning of life]. - Moscow: AST, 2004.

8. Ponomarev P.A., Roudenko A.M., Samygin S.I. The Value of Russian religious philosophy of XIX - beginning of XX century in spiritual and moral education of young people// Mediterranean Journal of Social Sciences. 2015. - Vol. 6. — №2. - P. 1.

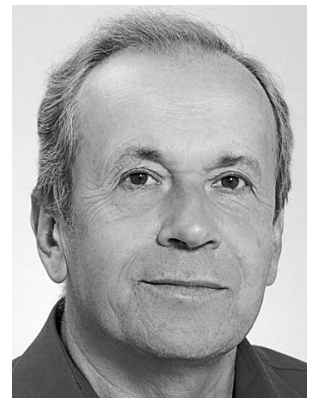

Пономарев Петр Андреевич - доктор философских наук, ведущий научный сотрудник Донского государственного технического университета.

Ponomarev Pyotr Andreevich - Doctor of Philosophical Sciences, Leading Researcher, Don State Technical University. 


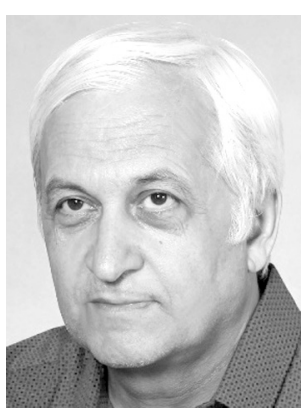

Панычик Александр Владимирович - философ, доцент кафедры Философии и культурологии Ростовского государственного экономического университета (РИНХ). Стаж работы в научно-исследовательской сфере - 20 лет. Сфера научных интересов: философия религии и философские проблемы эзотеризма.

Panychik Alexander Vladimirovich - Philosopher, Associate Professor of the Department of Philosophy and Cultural Studies of the Rostov State University of Economics (RSUE). Work experience in the research field is 20 years. Research interests: philosophy of religion, philosophical problems of esotericism.

344002, г. Ростов-на-Дону, ул. Б. Садовая, 69 69 B. Sadovaya st., 344002, Rostov-on-Don, Russia

E-mail: alexpgr@yandex.ru 